\title{
The land-sourced pollution in the Jiaozhou Bay ${ }^{*}$
}

\author{
GAO Zhenhui (高振会) $)^{\dagger}$, YANG Dongfang $(\text { 杨东方 })^{\dagger, \dagger+, \dagger \dagger, * *}$, QIN Jie (秦洁) $)^{\dagger}$, \\ XIANG Lihong $(\text { 相利宏 })^{\dagger}$, ZHANG Ke (张柯 $)^{\dagger}$ \\ ${ }^{\dagger}$ Beihai Monitoring Center, State Oceanic Administration, Qingdao 266033, China \\ ${ }^{\prime \prime}$ College of Fishery Science, Shanghai Fisheries University, Shanghai 200090, China \\ ${ }^{\dagger H}$ State Key of Urban and Regional Ecology, Research Center for Eco-Environmental Science, Beijing 100085, China
}

Received Aug. 11, 2006; revision accepted Dec. 9, 2007

\begin{abstract}
In recent years, natural environment of the Jiaozhou Bay has been changed largely by fast developing industry and agriculture of the cities around, from which wastewaters were generated. The size of the bay has been continuously shrunk with reduced river flows, resulting in serious contamination to the marine lives in the bay. After analyzing the basic historical data, the authors put forward a suggestion of how to protect the bay ecology for sustaining the resources in the Jiaozhou Bay.
\end{abstract}

Keyword: nutrients nitrogen and phosphorus; land-sourced pollution; red tide; Jiaozhou Bay

\section{NATURAL ENVIRONMENT}

The Jiaozhou Bay $\left(35^{\circ} 55^{\prime}-36^{\circ} 18^{\prime} \mathrm{N}\right.$, $120^{\circ} 05^{\prime}-120^{\circ} 25^{\prime} \mathrm{E}$ ) is located in the border of the Yellow Sea, south of Shandong Peninsula, and surrounded by Qingdao City. It is a typical semi-closed fan-shaped natural bay with $423 \mathrm{~km}^{2}$ in area and $c a .7 \mathrm{~m}$ in mean depth. It opens towards southeast to the Yellow Sea. Jiao-Ji Railway and Jiao-Huang Railway run around the bay in connection to the famous Qingdao Harbor, forming up an economic circle around the bay.

Dagu River is the largest contributive to the bay originating from the Mountain Fu in Zhaoyuan City. The drainage area of Dagu River is about 4631.3 $\mathrm{km}^{2}$, and its total length is $179 \mathrm{~km}$. Additionally, more than 10 rivers are around the bay, these rivers would have no natural runoff ultimately with increasing human activities, and the upper reaches of these rivers dry out year by year and the middle and downstream become channels of industrial wastewater and domestic sewage.

\section{LAND-SOURCED POLLUTION}

There are 11 main contributive rivers, Fushan, Haipo, Licun, Banqiaofang, Loushan, Wantou, Moshui, Zhuhe, Zehe, Yunxi and Fenghe. The amount of the runoff entering the sea is $5 \times 10^{8} \mathrm{t} / \mathrm{a}$.
More than $1.3 \times 10^{8} \mathrm{t}$ of wastewater is discharged into the 11 rivers taking $75 \%$ of the total city sewage.

Based on the monitoring result of 1997 in Report on Marine Environmental Quality of Qingdao issued by Beihai Monitoring Center (BMC), State Oceanic Administration (SOA) (confidential internal documents, the same hereafter in this paper or otherwise mentioned), 11 contaminants exceeded the standard in Fushan River, among them, the concentration of ammonia was 89.1 times over the standard, and COD 35.4 times. In Haipo River ammonia and maximal oil contents exceeded the standard by 76.7 and 59 times respectively. Wastewater disposed by Haipo Sewage Treatment Plant contained suspended matters, ammonia, and COD in high concentration that was respectively 2.6-fold, 2.24-fold and 15.3-fold of the standard. Oil, ammonia, and COD of Licun River exceeded the standard by times of 23.5, 20.2 and 16.84 respectively, and 36.1 and 37.1 times in oil and ammonia concentration for Banqiaofang River respectively. Moreover, volatile phenol

\footnotetext{
* Funded by Key Laboratory of Marine Spill Oil Identification and Damage Assessment Technology, SOA (No. 07EMC08), the Director's Foundation of the Beihai Monitoring Center (No. 005EMC16) and Chinese Academy of Sciences (No. KZCX 2-207).

** Corresponding author: dfyang@shfu.edu.cn
} 
concentration also increased. The situation in Loushan River was more serious, where concentrations of oil, $\mathrm{COD}$ and $\mathrm{Cr}^{6+}$ exceeded the standard by 29.2, 15.88 and 159 times respectively. In Wantou River the concentration of COD and oil exceeded the standard by 5.16 and 24.6 times respectively. Similarly did in Zhuhe, Zehe, Yunxi and Fenghe Rivers.

Four large-scale investigations taken by BMC on land-sourced pollution in 1989, 1996, 1997, and 2000 showed that the total annual wastewater discharged from Qingdao City stayed high at about $2 \times 10^{8} \mathrm{t}$ (Fig.1). Among them, industrial wastewater and domestic sewage took $50 \%$ each. The amount of the wastewater in 2000 was $15.54 \%$ more than that in 1989. The amount of domestic sewage rose by $38.80 \%$ and industry wastewater by $7.39 \%$. The concentration of all 8 contaminants doubled the benchmarks of both national and provincial standards. Although the amount of pollution substances discharged from the city in 2000 declined slightly compared to that of 1996, the pollution was still quite severe.

The water quality of the 11 drainage rivers is of organic pollution and inorganic nitrogen pollution, and the main pollution substances included suspended matters, COD, ammonia, and inorganic phosphorus. A few rivers were subjected to additional heavy metal pollution. Compared with that of 1996, the water quality of most rivers was somewhat improved but still very unoptimistic, for having over six times of regarding standard. Evaluated by "W's value" method in the Report on Marine Environmental Quality of Qingdao, the water quality of each river was "grave pollution" in grade. A large amount of wastewater and pollutants were discharged into Jiaozhou Bay, and caused serious pollution in coastal water.

\section{POLLUTION IN THE JIAOZHOU BAY}

The monitoring data taken by BMC over many years in history indicate that the main contaminants to the Jiaozhou Bay were N, P, COD, and oil, and the pollution of $\mathrm{N}$ and $\mathrm{P}$ was most serious. Especially, the eastern coast was the central area for receiving pollutants from industries and residents, and became the main polluted place.

The pollution degree in Haipo River Estuary, an aquiculture area between Hongshiya and Xuejiaodao was very high with $\mathrm{N}$, heavy metal, and COD; and in wet season, more serious with more

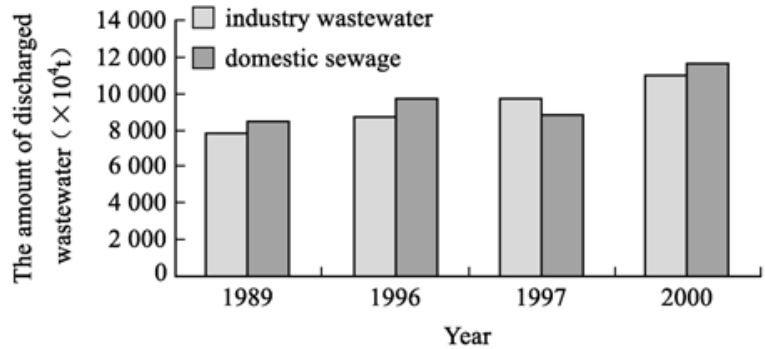

Fig.1 The amount of discharged wastewater

polluted second grade water according to the national code regarded.

The analysis on the observational data of the past few years with comprehensive estimation shows that $90 \%$ of the sea area of the bay qualified the first grade, while the polluted second grade water distributed mainly in the eastern part along the bay was around $7 \%$, and the third grade one was found in Haipo River estuary and Licun River estuary taking about $3 \%$ of the investigated area.

In 2002 and 2003 the Jiaozhou Bay pollution remained still very serious. The main pollutants were inorganic $\mathrm{N}, \mathrm{P}, \mathrm{Pb}$ and $\mathrm{Hg}$. Among them, inorganic $\mathrm{N}$ on the east shore area was the main pollutant, resulting in the third grade seawater, while the concentrations of $\mathrm{P}$ and $\mathrm{Hg}$ in the east of the bay and $\mathrm{Pb}$ in the southwest of the bay were high and exceeded the first grade seawater quality code.

In 2004, the rivers mouths areas were still heavily polluted, whereas the coastal areas of the Jiaozhou Bay became cleaner, and most places of the bay were clean (Fig.2).

\section{TREND OF ECOLOGICAL CHANGE IN JIAOZHOU BAY}

Land-sourced pollution is the main source of $\mathrm{N}$ and $\mathrm{P}$ import to seashore, and the two elements are responsible for constant or frequent eutrophication. The frequency of red tide outbreak would reduce if the eutrophication can be declined. The more serious eutrophication is, the higher the chance of the outbreak occurs. Therefore, the increase in nutrient $\mathrm{N}$ and $\mathrm{P}$ input from river is the key reason for frequent occurrence of red tide. At the starting point, human beings should be responsible for $\mathrm{N}$ and $\mathrm{P}$ in the sea. As land-sourced pollutant are dumped into the sea, the areas nearshore are contaminated, which would no doubt cause $\mathrm{N}$ and $\mathrm{P}$ pollution then the red tide outbreak (Fig.3). 


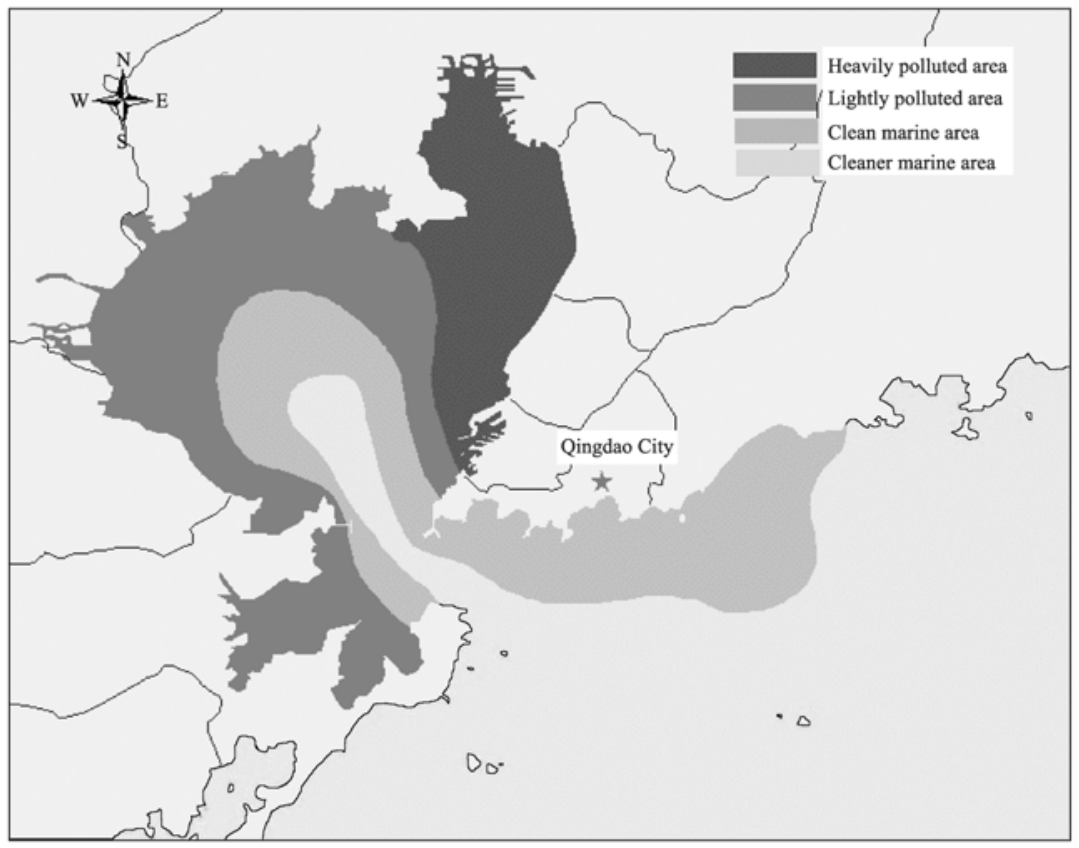

Fig. 2 The distribution of polluted marine areas in Jiaozhou Bay in 2004

A Gymnodinium sanguineum red tide during August-September 1998 happened in the Sishili Bay in Yantai, north of the Shandong Peninsula covered an area around $100 \mathrm{~km}^{2}$. A large-scale red tide in August-October 1989 in the Bohai Bay and Laizhou Bay caused economic loss of more than 300 million Yuan. Another large-scale red tide burst in August-October 1998 in Bohai Sea coast in area of $5000 \mathrm{~km}^{2}$, and caused a direct economic loss of 5.61 hundred million Yuan (Qi, 2003; Huang, 1994; SOA, 2000-2003). Both expansion and duration of deleterious red tide have been on the rise in the world (Sounia, 1995).

In past decades, the concentrations of $\mathrm{N}$ and $\mathrm{P}$ in the Jiaozhou Bay have been increasing, while Si maintained its yearly cycle variation (Yang, et al., 2000; 2001; 2002a, b; 2003a, b). However, due to river embankment construction, Dagu River, the main contributor to the Jiaozhou Bay has been disabled in transporting $\mathrm{Si}$, especially in dry-out season, making Si-limitation even worse to the marine primary production and biomass depletion (Yang et al., 2005a, b; 2006a, b, c, d, e).

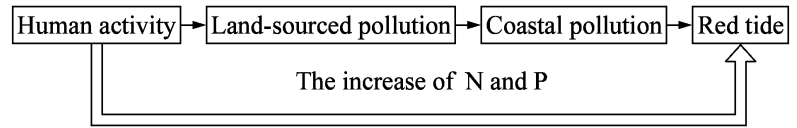

Fig.3 The relationship of mankind activity and red tide
A red tide can deteriorate the marine ecological environment, and affect tourism and mariculture. Some poisonous sorts may endanger the public in a long period.

\section{CONCLUSION}

Historical data from 1997-2003 taken by the Beihai Monitoring Center, State Oceanic Administration, China, were analyzed. The results of analysis show that the pollution to the Jiaozhou Bay has been worsen caused by industrial and household wastewater discharges from surrounding Qingdao City, a middle-sized Chinese city with urban population about 3 million, and other satellite towns, via a dozen of contributive rivers to the bay. Since 2004, the situation became controlled with cleaner coastal zones and marine waters. However, task of remediation of the area and resume of the normal ecological function of the bay remain heavy; more enforcement actions to ban random discharge without treatment and more researches on scientific countermeasures and the implementation, are called for.

Therefore, counteraction should be taken. First, industrial wastewater and domestic sewage must be treated then discharged up to the standard regarded. Water quality must be monitored and administrated and with well-established water quality codes. 
Second, human activities such as harbor or dike construction, and dredging sediment, measures must be taken to prevent contaminant from diffusion and constantly monitored. Third, research should be carried out on techniques of forecast, prevention and restraint of red tide in the areas that suffered or potentially would be suffered from red tide. Finally, a special protection zone should be allocated in the Jiaozhou Bay free of human impact.

\section{Reference}

Huang, Z. A., 1994. Red Tide Catastrophe, Ocean Press, Beijing. (in Chinese)

Qi, Y. Z., 2003. Chinese Coastal Red Tide, Science Press, Beijing. (in Chinese)

State Oceanic Administration, 2000-2003. State Oceanic Environmental Communique. (in Chinese)

Sounia, A., 1995. Red tide and marine phytoplankton of the world ocean: an inquiry into biodiversity. In: Harmful Marine Algal Blooms. Lassus P, Arzul G, Denn E. eds. England: Intercept.

Yang, D. F., H. Li, Y. M. Zhang, Y. L. Sun and J. Yang, 2000. The factor and way of limiting nutrient for the growth of phytoplankton. Marine Sciences 24(12): 47-50. (in Chinese)

Yang, D. F, J. Zhang, Y. Chen, Y. L. Sun and Y. F. Yang, 2001. The uniqueness of nutrient limitation. Marine Sciences 25(12): 49-51. (in Chinese)

Yang, D. F, Z. H. Gao, Y. Chen, Z. Liu and D. W. Ding, 2002a. The biogeochemical process of silicon. Marine Sciences 26(3): 35-36. (in Chinese)

Yang, D. F., J. Zhang, J. B. Lu, Z. H. Gao and Y. Chen, 2002b. Examination of silicate limitation of primary production in the Jiaozhou Bay, North China I: Silicate being a limiting factor of phytoplankton primary production. Chin. J. Oceanol. Limnol. 20(3): 208-225.

Yang, D. F., J. Zhang, Z. H. Gao, Y. Chen and P. Y. Sun, 2003a. Examination of silicate limitation of primary production in the Jiaozhou Bay, North China II: Critical value and time of silicate limitation and satisfaction of the phytoplankton growth. Chin. J. Oceanol. Limnol. 21(1): 46-63.

Yang, D. F., Z. H. Gao, Y. Chen, J. Zhang and P. G. Wang, 2003b. Examination of silicate limitation of primary production in the Jiaozhou Bay, North China III: Judgment method, rules and uniqueness of nutrient limitation among N, P, and Si. Chin. J. Oceanol. Limnol. 21(2): 114-133.

Yang, D. F., Y. Chen, Z. H. Gao, J. Zhang and F. Wang, 2005a. Silicon limitation on primary production and its destiny in Jiaozhou Bay, China IV: Transect offshore the coast with estuaries. Chin. J. Oceanol. Limnol. 23(1): 72-90.

Yang, D. F., Z. H. Gao, P. G. Wang, P. Y. Sun and S. Liu, 2005b. Silicon limitation on primary production and its destiny in Jiaozhou Bay, China V: Silicon deficit process. Chin. J. Oceanol. Limnol. 23(2): 169-175.

Yang, D. F., Z. H. Gao, P. Y. Sun, B. Zhao and M. Li, 2006a. Spatial and temporal variation of the primary production limited by nutrient silicon and water temperature in Jiaozhou Bay Advances in Marine Science 24(2): 203-212.

Yang, D. F., Z. H. Gao, P. Y. Sun, S. Zhao, and Y. C. Zhang, 2006b. Silicon limitation on primary production and its destiny in Jiaozhou Bay, China V: The ecological variation process of the phytoplankton. Chin. J. Oceanol. Limnol. 24(2): 186-203.

Yang, D. F., Z. H. Gao, Y. B. Yang, P. Y. Sun and P. X. Wang, 2006c. Silicon limitation on primary production and its destiny in Jiaozhou Bay, China VI: The complementary mechanism of the earth ecosystem. Chin. J. Oceanol. Limnol. 24(4): 401-412.

Yang, D. F., Z. H. Gao, P. G. Wang, Z. J. Yu and Q. Shi, 2006d. Mechanism of nutrient silicon and water temperature on phytoplankton. Marine Environmental Science 2006, 25(1): 1-6.

Yang, D. F., Z. H. Gao, Y. Ma, P. Y. Sun, and Y. B. Yang, 2006e. Influence of Jiaozhou Bay environmental change on marine biological resources, Marine Environmental Science 25(4): 39-42.

Correction:

In the paper of R. O. KAREEM et al., published in Vol. 26 No. 1, P. 104-115, 2008 with the DOI of 10.1007/s00343-008-0104-6, the country name in the title and keyword list should be Nigeria instead of Niagara. The Editor apologizes for this mistake. 